\title{
CORPUS E GÊNEROS TEXTUAIS COMO FERRAMENTAS NO ENSINO DE TRADUÇÃO NO PAR DE LÍNGUAS ESPANHOL/PORTUGUÊS PARA FINS PROFISSIONAIS
}

\author{
Viviane Cristina Poletto Lugli ${ }^{1}$
}

\begin{abstract}
Resumo
Este artigo apresenta o modo como gêneros textuais e corpus podem contribuir para o ensino de tradução no par de línguas espanhol/português. Consideramos que, no atual contexto de internacionalização do Brasil, no qual empresas de diferentes setores exportam para os países do Mercosul e a livre circulação permite aos cidadãos se deslocarem de um país ao outro por oportunidades de emprego ou residência, abrem-se diferentes possibilidades de trabalho com a tradução. No entanto, no cenário latino-americano de formação dos alunos de Secretariado, em que as línguas espanhola e portuguesa atuam como veículos que favorecem a integração entre os países mercosulinos, ainda carecemos de dicionários especializados, os quais auxiliem na prática de tradução. Desse modo, concebemos os gêneros textuais como práticas sociais indispensáveis para o ensino/aprendizagem de tradução em espanhol, assim como o corpus disponibilizado pelo CREA e o Corpus del Español del Siglo XXI, que permitem, ao estudante de tradução, a apropriação de conhecimentos relevantes envolvidos com o processo tradutório. Trata-se de uma pesquisa diagnóstica e bibliográfica que aponta o corpus como ferramenta potencializadora na tomada de decisões durante o processo tradutório.
\end{abstract}

Palavras-chave: tradução, ensino, gêneros textuais, corpus, ferramenta.

\section{CORPUS AND TEXTUAL GENDERS AS TOOLS IN TRANSLATION TEACHING IN THE SPANISH/PORTUGUESE LANGUAGES PAIR FOR PROFESSIONAL PURPOSES}

\begin{abstract}
This article presents how textual genres and corpus can contribute to translation teaching in the Spanish/Portuguese languages pair. We believe that, in the current context of internationalization in Brazil, in which companies from different sectors export to Mercosur countries and the free circulation allows citizens to move from one country to another for employment or residence opportunities, different possibilities of work with translation are open. However, in the Latin American scenario of the students training in the Secretarial course, where the Spanish and Portuguese languages act as vehicles that favor the integration between the Mercosur countries, we still lack specialized dictionaries, which aid in the practice of translation. In this way, we conceive textual genres as indispensable social practices for the teaching/learning process of Spanish translation, as well as the corpus provided by CREA and the Corpus del Español del Siglo XXI, which allow to the translation student the appropriation of the relevant knowledge involved with the translation process. This diagnostic and bibliographical research points out the corpus as a potential tool on the decisionmaking during the translation process.
\end{abstract}

Key words: translation, teaching, textual genres, corpus, tool.

\section{CORPUS Y GÉNEROS TEXTUALES COMO HERRAMIENTAS EN LA ENSEÑANZA DE TRADUCCIÓN EN EL PAR DE LENGUAS}

\footnotetext{
1 Universidade Estadual de Maringá (UEM), Maringá - PR - Brasil. Docente. Departamento de Letras Modernas. ORCID < https://orcid.org/0000-0003-4164-880X>. E-mail: vivianelugli@yahoo.com.br
} 


\section{Resumen}

\section{ESPAÑOL/PORTUGUÉS PARA FINES PROFESIONALES}

Este artículo presenta el modo como géneros textuales y corpus pueden contribuir para la enseñanza de traducción en el par de lenguas español/portugués. Consideramos que, en el actual contexto de internacionalización de Brasil, en el cual empresas de diferentes sectores exportan para los países del Mercosur y la libre circulación permite a los ciudadanos trasladarse de un país al otro por oportunidades de trabajo o residencia, se abren diferentes posibilidades de trabajo con la traducción. Sin embargo, en el escenario latino-americano de formación de los alumnos de Secretariado, en que las lenguas española y portuguesa actúan como vehículos que favorecen la integración entre los países mercosulinos, aún carecemos de diccionarios especializados que contribuyan a la práctica de traducción. De ese modo, concebimos los géneros textuales como prácticas sociales indispensables para la enseñanza/aprendizaje de traducción en español, así como el corpus disponible por el CREA y el Corpus del Español del Siglo XXI, que permiten, al estudiante de traducción, la apropiación de conocimientos relevantes relacionados con el proceso traductor. Se trata de una investigación diagnóstica y bibliográfica que considera el corpus como herramienta potenciadora en la toma de decisiones durante el proceso traductor.

Palabras clave: traducción, enseñanza, géneros textuales, corpus, herramienta.

\section{Introdução}

O ensino e a prática de tradução da língua espanhola, no Brasil, resulta do impacto gerado pelo contexto de internacionalização que envolve as esferas política, cultural e social. São essas esferas que determinam, no âmbito da tradução, o par de línguas a ser promovido nos ambientes administrativos, educacionais, culturais e inter-relacionais possibilitado pela dinamicidade do mercado. O mercado de trabalho, por sua vez, condiciona as competências profissionais requeridas para o profissional de Secretariado Executivo.

Com o desenvolvimento das tecnologias da comunicação e da competitividade, em que o maior valor é atribuído aos recursos comercializáveis e, à agilidade na prestação de serviços, visto que os próprios contatos entre clientes, empresas e tradutores se realizam online, buscando a presteza nos processos de negociações, a busca pela excelência no exercício das funções dos novos profissionais de Secretariado pressupõe, portanto, não apenas o conhecimento de ferramentas adequadas que lhes auxiliem em seu fazer profissional, como o seu engajamento com esse novo contexto de integração promovido pela globalização. Esse contexto, por sua vez, envolve a questão digital, normativa, socioeconômica e pragmática, uma vez que traduzir em espanhol-português, significa encontrar-se diante do desafio de transitar entre diferenças culturais e atender às diferentes expectativas em uma língua que se utiliza como materna e com inúmeras variações em 21 países.

Nesse cenário, a língua espanhola, por meio do ensino e da tradução, assume seu papel como veículo intercultural necessário e indispensável à comunicação, especialmente, na 
América do Sul, que torna possível a articulação e a relação entre os mercados internacionais e as exigências do mercado atual.

Nesse eixo de ação, a tradução é vista como uma atividade comunicativa complexa por ser corresponsável pela mediação resultada em um ato comunicativo que precisa refletir outro ato preexistente, em meio a uma cultura situada entre fronteiras. Tais atos, na tradução para fins profissionais a que nos referimos neste artigo - que se centra nas traduções realizadas com propósitos estritamente de documentação arquivística e documental - geralmente, exercem uma função prescritiva por orientarem ações a serem realizadas ou por descreverem ações enquadradas em um contexto de registro e de arquivos. É durante esse ato de mediação da comunicação, que se manifesta um uso autêntico e proposital da língua espanhola, que o tradutor se sente entre muros linguísticos-discursivos, os quais o levam à procura de soluções, nem sempre encontradas nos dicionários disponíveis para fins profissionais na esfera especializada ${ }^{2}$.

Essa é uma constante no fazer diário do tradutor, razão pela qual nos sentimos motivados, neste artigo, a refletir sobre um dos gêneros textuais que emerge na tradução que faz parte dessa esfera e que é denominada tradução pública.

A tradução pública resulta do Decreto presidencial $n^{0} 13.609$, de 21 de outubro de 1943, e demonstra a necessidade de tradução na produção de efeitos em repartições da União, dos Estados, dos Municípios, em qualquer instância, orientada pelos poderes públicos. Demonstra o que afirma Benjamim (1994): a tradução é necessária à "sua sobrevivência", para gerar poderes e direitos e é, portanto, uma necessidade humana.

É tão necessária que as primeiras nomeações de Intérpretes e Tradutores no Brasil ocorreram em 1808, com a vinda do Príncipe Regente D. João e sua corte, de acordo com Oliveira (2005).

Desse modo, embora a tradução remonte a uma longa data, a complexidade da tarefa, no caso da língua espanhola, ainda se faz presente e reflete nesse âmbito, por meio de, pelo menos, dois fatores: i) por manifestar uma necessidade comunicativa humana imposta pelo contexto político e socioeconômico, o que a caracteriza como um produto da realidade social; ii) por tratar-se de um ato comunicativo em que o sentido das palavras espelham significados ressonantes em diferentes culturas ${ }^{3}$, cujo destecer dos sentidos depende de um trabalho

\footnotetext{
2 Entendemos por esfera especializada toda esfera portadora de um léxico especializado, técnico, que se diferencia do léxico de língua geral presentes em dicionários semasiológicos, os quais são insuficientes para o trabalho do tradutor.

${ }^{3}$ Afirmamos isso por entendermos que os significados apresentados são resultados de pretensões dos indivíduos engajados na instância da enunciação, o que torna, algumas vezes, os seus sentidos incontornáveis. Somando-se
} 
colaborativo entre tradutor e recursos tecnológicos, como dicionários atualizados que reflitam a dinamicidade da língua, corpus comparáveis e corpus informatizados, os quais facilitem o contato com mostras autênticas de gêneros textuais presentes no uso da língua-alvo para a realização de escolhas léxicas decisivas na tradução.

Assim, embora a comunicação se concretize por meio de gêneros textuais convencionalizados, segundo as esferas em que emergem, não deixa de refletir também a autenticidade $^{4}$ de uso em mais de uma vintena de países e a necessidade do dizer em contextos sócio-históricos específicos, o que leva à formatação de cada gênero, de acordo com suas próprias características não apenas linguísticas, mas também composicionais. Por essa razão, a tradução tem uma natureza polifacética, segundo Hatim e Mason (1995), o que nos motiva a estudá-la com vistas a compreendê-la cada vez melhor, a fim de transpô-la no ensino que prepara profissionais cuja atuação pode ser tanto nas esferas de poder público, quanto nas diferentes empresas exportadoras e importadoras que expedem ou recebem documentos traduzidos.

Portanto, a tradução em contextos de linguagem especializada reflete uma realidade política, econômico-social e um caminho instigador de compreensão para o ensinoaprendizagem.

Entendendo que o trabalho didático nas Universidades parte das práticas sociais em uso na sociedade e que o ensino de tradução para fins profissionais requer o contato e a familiarização entre os diferentes modos autênticos de expressão da língua, emoldurados por meio dos gêneros textuais que emergem no meio institucional-empresarial, torna-se, por conseguinte, ineficiente a abordagem didática que parte de modelos de língua fabricados para o ensino, neste contexto de globalização.

Nessa perspectiva, ao considerarmos que toda a esfera de uma língua se desenvolve por meio de textos, os quais são seus instrumentos de interação e megaferramentas para o ensino (SCHNEUWLY, 2004), propomos que o ensino de tradução em língua espanhola considere os gêneros e os demais recursos textuais que a Linguística de Corpus oferece, de modo aos aprendizes vislumbrarem usos reais e comparáveis de expressões lexicais empregadas nos diferentes países de língua espanhola que se apresentam como obstáculos na tradução. A Linguística de Corpus, nesse sentido, tende a ser um instrumento essencial ao trabalho do tradutor.

a isso, consideramos o fato de a língua espanhola ser falada em 21 países, os quais apresentam as suas diferenças léxicas no contexto de tradução pública.

${ }^{4}$ Referimo-nos à autenticidade, pois compreendemos que os textos são produzidos com objetivos específicos e por não se tratar de textos fabricados para o ensino, mas produzidos em atos reais de comunicação. 
Partimos da concepção de que os corpora e dicionários são no ensino de tradução instrumentos de trabalho e os gêneros textuais são, como afirma Schneuwly (2004), objeto de ensino. Em consonância com essa concepção, cabe à universidade levar o aprendiz não somente à apropriação do instrumento/gênero, com o qual precisará mediar as ações de linguagem em sua esfera de trabalho, mas também ao desenvolvimento de competências que lhe permita agir adequadamente no processo de retextualização do gênero que lhe caberá traduzir.

Nesse contexto, torna-se sine qua non desenvolver, nos acadêmicos do curso de Secretariado Executivo em que trabalhamos, capacidades que atendam à realidade dos modos de interação em seu trabalho (HYMES, 1973 apud BRONCKART, 2009, p.190). Essas capacidades são denominadas segundo Bronckart (2009, p.190) competências de acordo com a análise do trabalho, competências que partem da análise das atividades coletivas, nas quais se avaliam a eficácia e a performance (BRONCKART, 2009, p.190) dos indivíduos confrontados às tarefas e, de aí, deduzem-se as competências exigidas para que a performance de um determinado profissional seja mais satisfatória.

Conforme Tardiff (1994, apud BRONCKART, 2009, p.190), a competência significa "um sistema de conhecimentos declarativos, condicionais e procedurais, organizados em esquemas operatórios que permitem a resolução de problemas”. O trabalho com a tradução requer todo esse tipo de sistema de conhecimentos e, por isso, precisa ser alvo no ensinoaprendizagem, de forma que demonstre não apenas que ela existe por ser uma necessidade humana, mas que há modos de solucionar problemas emergentes durante a sua execução.

Compreendendo que o cerne do trabalho do profissional de Secretariado são assessoria, gestão e resolução de problemas, e uma de suas funções na empresa é a tradução, torna-se claro que não basta oferecer aos acadêmicos um ensino pautado apenas em modelos fixos de gêneros para traduzir, formulários selecionados por materiais didáticos, nem sempre correspondentes à realidade dinâmica das situações reais de comunicação, mas sim faz-se necessário um deslocamento do olhar para as diferentes possibilidades de tomada de decisões na tarefa de traduzir ou, até mesmo, apenas compreender ${ }^{5}$ os diversos enunciados que podem fazer parte de sua esfera laboral.

A concepção que orienta este trabalho é de que todos os textos são produtos

\footnotetext{
5 Afirmamos que alguns secretários necessitam apenas compreender, por entendermos que, em algumas empresas, a função do profissional de secretariado não exige nada além da compreensão do texto traduzido ou do texto na língua estrangeira, pois alguns gêneros textuais somente podem ser traduzidos por tradutores juramentados, ofício alcançado apenas por profissionais que passaram nos concursos públicos oferecidos por Juntas Comerciais do Estado.
} 
resultantes de tomadas de decisões, pois não se geram a si mesmos. Logo, o profissional, ainda que não precise traduzir, mas esteja unicamente realizando a leitura de um gênero traduzido, também estará tomando decisões ao negociar os significados presentes no texto. Como afirma Gadamer (1976, apud HERMANS, 1996, p. 2), a tradução está totalmente vinculada à leitura, pois ler é interpretar, e a interpretação pode determinar o resultado da tradução. Assim, tal tomada de decisões estará grandemente favorecida pelo auxílio que os corpora linguísticos já informatizados e disponibilizados na web podem oferecer ao tradutor e no ensino-aprendizagem de espanhol.

Nesse sentido, abordamos neste trabalho a necessidade de atrelar o ensinoaprendizagem da tradução aos gêneros textuais autênticos e por meio dos recursos oferecidos pela Linguística de Corpus. Nossa abordagem se justifica pelo fato de considerarmos que os corpora linguísticos disponibilizam mostras autênticas de usos da língua, refletindo, no caso da língua espanhola, a internacionalização do conhecimento, visto que trazem o uso do idioma em todos os países em que é utilizado como língua materna. Assim, as mostras autênticas em língua espanhola são altamente eficazes na compreensão dos modos de manifestação do dizer, por meio dos gêneros a serem traduzidos e compreendidos, constituindo-se, desse modo, uma importante ferramenta no auxílio do ensino-aprendizagem.

Portanto, este artigo está organizado em 3 tópicos: i) o primeiro, em que demonstramos a concepção de tradução a qual nos filiamos; ii) o segundo, em que expomos a relevância da Linguística de Corpus e gêneros para o ensino-aprendizagem de secretários executivos e para o trabalho do tradutor; iii) o terceiro, em que apresentamos exemplos da funcionalidade do corpus e do gênero textual na tradução de um gênero da esfera pública/profissional.

\section{Tradução: aspectos a serem considerados}

Com base na literatura especializada sobre tradução, entendemos a tradução como um modo de mediação entre culturas ${ }^{6}$, em que ressignificamos o texto 1 ao retextualizá-lo para um texto 2. Essa concepção se explica devido ao fato de a tradução ser o resultado da interpretação gerada pela leitura realizada pelo tradutor e de suas escolhas discursivas que estão relacionadas às condições de produção e de recepção de textos. Tais condições são resultados do contexto sócio-histórico em que os textos são gerados.

\footnotetext{
6 “... as línguas são inseparáveis da diversidade cultural...” (OUSTINOFF, 2011, p.10).
} 
Ao pensarmos que a tradução existe como uma necessidade e com a finalidade comunicativa de interação humana e que, portanto, faz parte do "labirinto infinito da linguagem" (ARROJO, 1999, p.23), não podemos deixar de pensar na instabilidade dos signos nela presentes, uma vez que a produção de textos se vale de recursos gramaticais e culturais que uma língua oferece, os quais são utilizados para codificar referentes de acordo com a intencionalidade nem sempre apreensível e as representações da comunidade interpretativa (FISH, 1992) da qual se escreve e para qual se escreve. Neste sentido, os textos são gerados em contextos diferentes, em que usuários de uma língua tratam aspectos linguísticos e socioculturais de modos diferentes, o que pode gerar arranjos textuais e significados diversos, tais como: organização de tema e rema no nível de uma oração; questões de predicação como o número de $\operatorname{argumentos}^{7}$ que o verbo exige em uma determinada cláusula; a posição que o sujeito de uma oração ocupa na sentença; se ele aparece na oração matriz (CASTILHO, 2012) ou na oração subordinada etc.

Como afirma Rodrigues (2000, p.187) “...seria impensável atribuir um mesmo valor a palavras de duas línguas diferentes". A autora explica que "não há como postular que os diferentes sistemas organizem seus componentes de modo a espelhar a organização do outro".

Tais palavras nos levam a refletir sobre os conceitos enraizados no pensamento tradicional relacionados às noções de equivalência e à sacralização do original proposta pelo linguista Eugene Nida (1975, apud ARROJO, 1999), que concebia a tradução como um transporte de significados, no qual aspectos espaço-temporais não seriam levados em consideração na tradução de uma obra.

As traduções, de acordo com a concepção tradicional, teriam como objetivo fazer que os receptores da língua original reagissem da mesma maneira que os receptores que lessem o texto traduzido, o que é, na perspectiva pós-moderna "impossível” (RODRIGUES, 2000), uma vez que as situações de produção dos textos são diferentes, os receptores e as realidades nunca são as mesmas, o que implica novas leituras e reescritura dos textos.

As realidades não coincidem e os referentes são diferentes porque os signos linguísticos utilizados pelo usuário de uma língua para comunicar-se estão revestidos de valores sintático, semântico e pragmático (DIK, 1997) que fazem parte de uma língua e de uma cultura que representa uma determinada comunidade interpretativa (FISH, 1992). A própria organização do tema (informação recuperável, anafórica, segundo Braga (1995)) e do rema - informação nova ou não recuperável no contexto) atende a propósitos culturais

\footnotetext{
${ }^{7}$ Berber Sardinha (2004, p.239) faz referência a essa particularidade das línguas ao explicar a prosódia semântica do verbo acontecer em inglês.
} 
específicos nas diferentes línguas estrangeiras e podem sofrer alterações que variam segundo "as escolhas conscientes ou inconscientes" dos usuários de uma língua (NEVES, 1997,p.60).

Por uma questão pragmática, o tema, geralmente, em nossa língua materna, é apresentado antes do rema, que é a informação nova. Para verter textos para outras línguas, portanto, aspectos como esse se tornam alvo de observação do tradutor para que ele possa organizar os enunciados do texto de chegada. A constatação de como se organizam as informações no texto em língua estrangeira, por meio de corpus, poderá levar, portanto, o tradutor a escolher, nas outras línguas, uma diferente organização sintática e pragmática da oração, o que pode gerar diferenças na retextualização (TRAVAGLIA, 2003) ou na reformulação (OUSTINOFF, 2011).

Oustinoff (2011, p.8) explica que "a tradução tem um alcance bem mais geral do que costumamos pensar, porque ela está presente no seio de toda língua, por meio da reformulação." Reformulações (OUSTINOFF, 2011), retextualizações (TRAVAGLIA, 2003), transformações (ARROJO, 1996) são escolhas que, por sua vez, estão atreladas aos frames $^{8}$ (MARCUSCHI, 2005) que os usuários de uma língua acionam durante a comunicação. Nesse sentido, Fairclough (2001) observa que não há como separar textos de cognição ${ }^{9}$ e, por isso, a tradução como afirma Rodrigues (2000), é diferença.

Para Derrida (2002), traduzir é transformar um texto em outro e, ao transformá-lo "a noção de fidelidade e de texto original precisa ser redefinida", segundo Arrojo (1999, p.23). Nesse eixo de ação, nossa tradução, de acordo com Arrojo (1999, p.44), será fiel "àquilo que consideramos constituí-lo...”, o que significa dizer que será fiel à interpretação do tradutor/leitor do texto de partida.

Arrojo (1999) afirma que o texto é uma máquina potencial de significados e, por isso, entende que visões de fidelidade remetem a uma concepção fechada de linguagem em que não se dialoga com uma série de questões, tais como modelos de interação, de representações de mundo, de organizações específicas da linguagem no sistema da língua etc. Visão semelhante à de Arrojo (1999) está na concepção de tradução a partir da perspectiva desconstrucionista preconizada por Rodrigues (2000), que não comunga o pensamento tradicional da tradução que situava o tradutor como aquele que não poderia cometer desvios na tradução e nem

\footnotetext{
${ }^{8}$ Segundo Marcuschi (2005, p. 63), as representações conceituais ou relações cognitivas são encapsuladas em modelos mentais, o que comumente se denomina frames (enquadres), "que representam focos implícitos armazenados em nossa memória de longo prazo como conhecimentos de mundo organizados."

9 Toury (1995, p.15-16) também se refere à cognição ao explicar sobre regras, normas e idiossincrasias nos estudos descritivos da tradução. Explica que a tradução está atrelada às possibilidades e às limitações do aparato cognitivo do tradutor como um mediador necessário. A cognição, para esse autor, também está associada à idiossincrasia, a fatores intersubjetivos que passam a ser considerados como normas.
} 
posicionar-se como sujeito constituído por formações discursivas e ideológicas, havendo assim um apagamento do sujeito-tradutor.

Tais visões - diferentemente das preconizadas por Nida (1975) e por Catford (1980), que se inserem no âmbito da Linguística e da tradução e que foram tomadas como referência durante muitos anos no ensino de tradução e nas discussões em torno de equivalências tradutórias — remetem à ideia de tradução como uma reconstrução, como uma ressignificação, uma vez que Rodrigues (2000) pretende demonstrar que a tradução trabalha na diferença entre o significante e significado e que a noção de signo/significante é desconstruída a partir de Derrida (2002), autor que inscreve o signo em uma cadeia de remissões e de substituições. Por conseguinte, traduzir implica também pensar em reconstrução, reescrita, retextualização, reformulação, enfim trata-se de uma tomada de decisões.

Portanto, para essa atividade complexa de reescrita, é possível contar com ferramentas que possam contribuir para as nossas análises textuais e interpretativas. Podemos utilizar recursos como corpus de língua espanhola e gêneros textuais que favoreçam a nossa tomada de decisões para explorarmos e para tentarmos entender a linguagem por meio de comparações de expressões, frequência de palavras que aparecem em um texto etc.

O primeiro recurso que temos disponível e que nos ajuda sobremaneira é um número significante de gêneros para a comparação de modelos de gêneros traduzidos. Outro recurso que contribui muito com o trabalho e ensino-aprendizagem de tradução são corpus em língua espanhola, sobre os quais passamos a comentar.

\section{Ferramentas para o ensino-aprendizagem de tradução: corpus e gêneros textuais}

De acordo com Berber Sardinha (2004), a Linguística de Corpus ocupa-se da coleta e da exploração de corpora, ou conjuntos de dados linguísticos textuais coletados, criteriosamente, com o propósito de servirem para a pesquisa de uma língua ou de uma variedade linguística. Como tal, dedica-se à exploração da linguagem por meio de evidências empíricas extraídas por computador.

A Linguística de Corpus nos oferece, desse modo, alternativas de análise para trabalhar com o texto a ser traduzido. Entre elas, citamos: i) estudar as características diferenciais ou universais da tradução (BAKER, 1993) em corpus paralelos de gênero textuais; ii) organizar lista de palavras presentes em corpus específicos, com gêneros textuais da esfera para a qual se traduz, para observar a funcionalidade da palavra em gêneros textuais 
que precisamos traduzir; iii) contrastar usos de léxicos presentes no corpus e a sua possibilidade de aplicação no texto que somos encarregados de traduzir; iv) inferir significados ausentes em dicionários de língua geral.

Logo, os recursos advindos dessa ciência, que trata de princípios de tradução baseada em dados, podem permitir ao tradutor analisar a funcionalidade na língua-alvo, como propõe Baker (1993). Isso porque o corpus se constitui por textos de uso autênticos em uma comunidade interpretativa, gêneros de textos selecionados para compô-lo com propósitos específicos.

Assim, ao concebermos o trabalho do tradutor como uma tarefa de mediação entre culturas, em que deslizamos nossas ações mentais entre os signos e significantes presentes nos gêneros textuais na tentativa de interpretá-los para a produção de um novo texto, torna-se uma ferramenta essencial utilizar corpora formado por textos autênticos em linguagem natural, com critérios determinados, de acordo com os objetivos de uma pesquisa, ensinoaprendizagem na tradução.

Para Berber Sardinha (2004), o corpus possui a função representativa por ser representativo de um idioma. Tal representatividade está associada à extensão do corpus, visto que quanto maior é o corpus, mais probabilidade há de se encontrar palavras raras.

Ao vivermos, durante a tradução, no interstício da incompreensão (SOBRAL, 2008), o corpus pode fornecer-nos pistas para nossas interpretações. Assim, ao entendermos que, ao traduzir, precisamos considerar os contextos de produção dos textos, uma vez que os usos da língua são datados, os significados são mutáveis e nem sempre comutáveis, corpus de referência para analisarmos fatos das línguas presentes nos gêneros textuais para fins profissionais contribuem grandemente para o trabalho do tradutor, visto que tais gêneros por estarem classificados entre os gênero secundários, de acordo com a classificação bakhtiniana de gêneros - não são familiares para os Secretários Executivos em formação e para o tradutor, requerendo desse modo, o olhar com lupas (CINTRÃO, 2002) do aprendiz/tradutor para encontrar um rearranjo dos signos a serem retextualizados.

Esse rearranjo na retextualização, portanto, está relacionado também ao conhecimento sobre o gênero textual, pois como afirma Ezpeleta (2005, p. 5) "los géneros son vectores importantes en la construcción de paradigmas, las ideologías, la forma de entender el mundo y las perspectivas culturales”. Eles são, consequentemente, meios orientadores da leitura.

Logo, corpus e gêneros são ferramentes indipensáveis para o ensino-aprendizagem de tradução para fins profissionais.

Em espanhol, contamos com dois corpus significativos no que se refere a sua 
representatividade: o CREA (Corpus de Referencia del Español Actual), com mais de 160 milhões de palavras, o qual visa a compartir recursos para estudos comparativos da língua utilizada nos países de expressões hispanoamericanas e espanhola; e o Corpus del español del siglo XXI, com 225 milhões de formas. São corpus que, de acordo com a definição de Berber Sardinha (2004), caracterizam-se como de amostragem por conterem porções de textos planejadas para serem uma amostra finita da linguagem como um todo.

Desse modo, como tradutores situados entre o nós e o outro e, consequentemente, em meio à diferença (RODRIGUES, 2000), uma vez que as palavras não são atemporais, mas contextuais, podemos utilizar corpus como esses, em conjunto com gêneros textuais cujo modelo será traduzido, que nos auxiliem a observar os padrões de uso mais recorrentes de determinadas palavras, pois, por meio da frequência de um traço linguístico, podemos entender como se comporta uma determinada palavra em um determinado gênero, em contexto autêntico, o que pode contribuir para as nossas escolhas nas atividades tradutórias e de ensino-aprendizagem de tradução.

Por meio de dados presentes em um corpus, conseguimos repensar nossas interpretações e hipóteses acerca do significado de uma determinada palavra no contexto em que ela se insere. Para demonstrar o modo como um único corpus ou diferentes corpus ou podem contribuir com o ensino-aprendizagem de tradução para estudantes de Secretariado Executivo, passaremos a apontar exemplos extraídos de um gênero textual que emerge na esfera da tradução pública no par de línguas espanhol-português.

\section{Exemplificação do corpus e do gênero como ferramenta no ensino-aprendizagem de tradução}

Como o objetivo de exemplificar como o corpus pode funcionar como ferramenta, no ensino-aprendizagem de tradução, selecionamos um exemplo de uma palavra presente no gênero certidão de casamento venezuelana.

Ilustraremos o uso da palavra Parroquia para demonstrar a relevância de corpora em nossa tomada de decisões, ao traduzir esse documento da tradução pública, por ter gerado diferentes interpretações no momento da tradução:

Acta número .... a las.... pm del día.......... constituídos los ciudadanos Ángel ${ }^{10}$ García y Josefa Gonzáles: Primera Autoridad Civil y secretario respectivamente de la Parroquia Macarao,

\footnotetext{
${ }^{10}$ Todos os nomes do excerto são fíctícios.
} 
Municipio Libertador del Distrito Capital, en el salón del despacho Compareció el ciudadano Juan Rodrígues, cédula de identidad número V....., de estado civil soltero, de profesión Deportista, de ..... años de edad, nacido el .... de noviembre de en Caracas parroquia San Juan y domiciliado en...

Ao pesquisarmos a palavra Parroquia no CREA (Corpus de Referencia del Español Actual) - Crea escrito - , encontramos 97 casos em 40 documentos da Venezuela ${ }^{11}$. Todos são substantivos e apresentam em sua maioria os significados de igreja, jurisdição ou território administrativo.

Logo, a quantidade de casos encontrada no Corpus já demonstra que essa palavra é comum na língua espanhola, pois há vários exemplos que nos levam a compreender que ela é mobilizada em diferentes situações, em documentos dos diversos países que compõem o Banco de dados do CREA.

Para demonstrar um exemplo de Parroquia com sentido de igreja, copiamos abaixo um excerto do gênero em que a palavra ocorre:

\section{Excerto I :}

Por estar pendiente de tales preocupaciones genealógicas, impropias de su edad y de sus predilecciones del sexto grado, obligado más bien por los deberes de la obediencia, se le fue la parte principal de la sabrosa conversación que el Señor Obispo de la Diócesis, de visita en Carora, y el Padre de la Parroquia de San Juan, sostuvieron toda la tarde en la sala contigua a la Sacristía que es donde está el archivo parroquial. Pero algo oyó Francisco, con inquietud de su ánimo.

Como é possível visualizar por meio do excerto ilustrado, O Corpus de referência, além de nos fornecer a palavra inserida em um tipo textual - que é a narração por estar relatando um acontecimento e estar inserido no gênero textual novela venezuelana - nos permite conhecer o ano da publicação da obra em que cada palavra pesquisada se insere (1986), o nome do autor (MORÓN, GUILLERMO), o título da obra (El gallo de las espuelas de oro), o país de publicação da obra (VENEZUELA), a editora (Monte Avila Editores

\footnotetext{
${ }^{11}$ Para facilitar a nossa tomada de decisões, optamos por fazer uma consulta por países, em que utilizamos o critério geográfico "Venezuela" e selecionamos os temas "Religião", "Novela" e "Direito. Por meio da ferramenta "Recuperar" conseguimos obter os exemplos referentes à palavra e associamos com o contexto do gênero textual que estávamos traduzindo. Vale explicar que o número de ocorrências da palavra " Parroquia", na totalidade dos documentos disponibilizados pelo CREA, atualmente, pois é um corpus que passou por uma atualização em 2018, é de 1741 casos, em 879 documentos. No entanto, optamos pela busca apenas pelo critério geográfico "Venezuela" por ser o país no qual teve origem o documento que traduzimos.
} 
(Caracas), 1993) e o tema (07.Novela).

Essas informações nos fornecem melhores condições para analisarmos a palavra, se compararmos a apenas uma análise feita por meio das definições apresentadas pelos dicionários, tornando-nos mais acessível aquilo que está inacessível pelos dicionários, uma vez que ainda que não é característica do gênero textual dicionário portar 40 usos de uma única palavra - devido à própria configuração do gênero, o número e organização do verbete - o que pode ser favorecido pelo corpus por ser informatizado, constantemente atualizado e mantido por uma associação de academias de línguas que constitui a Real Academia Espanhola.

Desse modo, como podemos observar, o corpus não define a palavra, mas é uma ferramenta que contribui para a interpretação do tradutor que pode inferir um sentido para a palavra inserida no gênero textual, principalmente quando já possui um conhecimento com relação ao funcionamento do gênero que orienta a leitura do tradutor.

Quanto ao exemplo de Parroquia, com sentido de jurisdição, ilustramos com parte ${ }^{12}$ do seguinte excerto extraído do Corpus:

\section{Excerto II:}

Pocas innovaciones contiene el Decreto Orgánico de los Tribunales del Distrito Federal, dictado el 7 de julio de 1900 por el General Cipriano Castro, por el cual se dispuso que habría un Juez para el Departamento Libertador y otro para el Departamento Vargas, con jurisdicción en su respectivo territorio, en lo Civil y en lo Mercantil; que en el Departamento Libertador habría dos jueces de Parroquia para todas las Urbanas, con jurisdicción en lo Civil y Mercantil y sede en el Centro de Caracas; que en cada Parroquia foránea habría un Juez de Parroquia con jurisdicción en lo Civil, en lo Mercantil y Criminal; que con la misma jurisdicción habría un Juez de Parroquia en las que forman el Departamento Vargas; que en el Distrito Federal habrían dos Jueces de Instrucción, uno para cada uno de los Departamentos que lo forman y sede en Caracas y La Guaira, respectivamente.

O excerto II demonstra que o emprego do vocábulo "Parroquia" também mobilizado em uma obra Venezuelana remete a um sentido totalmente diferente da mesma palavra no excerto I, visto que o excerto II se trata de um texto expositivo em que se expõe a respeito de inovações contidas em um Decreto de Tribunais do Distrito Federal. Dessa maneira, por meio do conhecimento do tipo textual (expositivo), inserido no Gênero livro da área de direito "Doutrina e testemunho", é possível compreender o sentido da palavra "Parroquia" como uma

\footnotetext{
${ }^{12}$ Não transcrevemos o excerto completo devido a sua extensão.
} 
palavra que reflete "poder de administração, de jurisdição", "poder que compete a uma determinada área de atuação". Tal compreensão também é facilitada pelas informações que o corpus porta como: o ano da publicação da obra em que a palavra se insere (1984), local de publicação (Dirección de Cultura, Universidad Central de Venezuela, Caracas)), o nome do autor (MEDINA, JOSÉ RAMÓN), o título da obra (Doctrina y testimonio), o país de publicação da obra (VENEZUELA) e o tema (03. Derecho). Essas informações complementares apresentadas pelo Corpus de Referencia del Español Actual reflete aspectos sócio-históricos - tais como o momento físico e o momento social da publicação que é a década de 80, na Universidade Central da Venezuela - o que remete à ideia de que o assunto era relevante para os estudos da época.

Todos esses dados demonstram que o léxico tem uma faceta dinâmica, seus usos são datados nos gêneros textuais e, no ensino-aprendizagem de tradução, é necessário considerar questões como essas para a sua compreensão e para as escolhas tradutórias adequadas.Outro exemplo da palavra Parroquia, cujo sentido é de território administrativo ou distrito, apresentamos no excerto III do texto extraído do Corpus:

\section{Excerto III}

Los trabajos se inician hoy

José Antonio Calo, presidente de la Corporación de Servicios Municipales de la Alcaldía de Caracas, indicó que una cuadrilla de hombres de ese despacho comenzará este miércoles en la -Parroquia El Recreo -a la cual pertenece la urbanización La Florida- los trabajos correspondientes a la poda adecuada de los árboles del sector, así como a la limpieza del alcantarillado.

O excerto III permite ao aluno compreender que o tipo de texto é expositivo e trata-se do gênero notícia no qual se demonstra, por meio do vocábulo "cuadrilla", que um grupo de homens indicados pela prefeitura se reunirá para podar as árvores do setor e fazer a limpeza dos bueiros.

Permite também ao aluno visualizar, por meio da palavra "cuadrilla", o que afirma Rodrigues (2000, p.187) de que é "impensável atribuir um mesmo valor à palavras de duas línguas diferentes". Isso porque o signo "cuadrilla" existe na língua portuguesa com uma grafia semelhante à grafia na língua espanhola; no entanto, o significado não é equivalente no par de línguas, pois enquanto na Venezuela se utiliza como um grupo de pessoas que se reúnem para desempenhar atividades profissionais em um bairro, na língua portuguesa é 
utilizada com o sentido de bando de ladrões, cavaleiros aprestados para a guerra, tipo de dança, etc.

Logo, este texto apresentado pelo Corpus, embora seja um pequeno excerto, facilita a compreensão do aluno com relação ao significado da palavra, ao mesmo tempo em que o corpus permite ao aluno atentar-se também ao uso de novas palavras que não são transparentes no texto, como Alcadía ${ }^{13}$, cuadrilla, despacho ${ }^{14}$, urbanización $^{15}$, sector ${ }^{16}$, alcantarillado $^{17}$. O aluno aprende, desse modo, que o desvendar de significados está envolvido a questões comunicativas e pragmáticas que situa um texto em relação ao seu contexto. O contexto demonstrado pelo Corpus de Referencia del Español Actual pode ser visualizado não somente pelos elementos coesivos do texto como "sector" que se refere ao Bairro "Recreo", mas também pelo ano da publicação da notícia (2001) em que a palavra se insere, o nome da instância enunciadora (Prensa ${ }^{18}$ ), o título da obra (El Universal, 03/10/2001: Árboles descuidados), o país de publicação (VENEZUELA ) e o tema (Diario El Universal C.A. (Caracas)).

Nesse sentido, compreendemos que o corpus aliado à compreensão do gênero textual é uma ferramenta no ensino-aprendizagem de espanhol para fins profissionais que pode preparar o aluno para o desenvolvimento de conhecimentos interculturais necessários nesse contexto de internacionalização em que o ensino precisa inserir-se. Ao entendermos que esse gênero em que a palavra se manifesta é classificado como notícia e que a palavra "Parroquia" apresenta um outro referente que é "urbanización”, é possível inferir o sentido de território administrativo para "Parroquia". É a partir dessa inferência que o tradutor busca no gênero a ser traduzido um contexto similar para decidir se esse significado pode ser encaixado no gênero textual que está encarregado de traduzir.São procedimentos, portanto, eficazes para o ensino-aprendizagem e por isso, concebemos corpus e gêneros como ferramentas, pois elas permitem a geração de capacidades (SCHNEUWLY, 2004) de uso da linguagem.

Após essa análise, podemos ainda proceder à busca da palavra Parroquia no Corpus del Español ${ }^{19}$ del Siglo XXI, suporte que é formado por textos escritos e orais ${ }^{20}$, em que

\footnotetext{
13 Prefeitura.

${ }^{14}$ Escritório, departamento.

15 Bairro.

${ }^{16}$ Sinônimo de espaço administrativo.

${ }^{17}$ Bueiro.

18 Jornal.

${ }^{19}$ Realizamos a pesquisa neste corpus também por apresentar dados documentais diferentes do CREA e por apresentar mais formas que o CREA.

${ }^{20}$ É importante esclarecer que esse corpus, quando consultado, em 2014, era ainda um recurso em construção e que, por isso, segundo a Real Academia Espanhola, informação disponível e acessada em 29 de jan.2019, em < http://web.frl.es/CORPES2/view/inicioExterno.view;jsessionid=987DE17B6758C944BFCB541BB2DDD5EE >,
} 
encontramos 600 registros da palavra, entre os quais os significados que mais ocorrem e que estão relacionados a este trabalho são os associados à Igreja e à divisão administrativa. Ocorrem também, em menor quantidade, com o significado de clientela e conjunto de indivíduos. Aparece apenas uma vez com sentido de ofício ${ }^{21}$, lugar em que se registra o nascimento, dados altamente relevantes na tomada de decisões.

Nesse eixo de reflexão, para ilustrar as ocorrências que poderiam ser trabalhadas no ensino-aprendizagem de tradução para fins profissionais, apresentamos os seguintes exemplos:

\section{I) Exemplo com o significado de Igreja:}

en la manera de recibir dignamente la visita. Pero por más que se devanaba la sesera, sacaba siempre en limpio que donde no hay harina todo es mohína, y que de los codos no salen lonjas de tocino. Reza el refrán que nunca falta quien dé un duro para un apuro; y por esta vez el hombre para el caso fue aquel en quien menos pudo pensar el cura; como si dijéramos, el último triunfo de la baraja humana, que por tal ha sido siempre tenido el prójimo que ejerce los oficios de sacristán y campanero de parroquia. Eralo de San jerónimo un indio que apenas podía llevar a cuestas el peso de su partida de bautismo, arrugado como pasa, nada aleluyado y que apestaba a miseria a través de sus harapos. Hízose en breve cargo de la congoja y atrenzos del buen dominico, y una noche, después del toque de queda y cubrefuego, acercóse a él y le dijo: - Taita cura, no te aflijas. Déjate vendar los ojos y ven conmigo, que yo te llevaré a donde encuentres mas plata

\section{II) Exemplo com o sentido de divisão administrativa}

sale, que es de carne, que es un espíritu, que muerde, que cocea, que busca chiquillos para sacarles el sebo, que los serenos, que la policía, que cazarla a tiros... y nadie se atrevía a pedirle el pasaporte. Al cabo, la delación de un pinche de billar hizo luz en el horrible caos, y el misterio se aclaró. ¿ Saben ustedes lo que era la Berrona? Una docena de marinos que salían de un café muy popular en Santander, por lo antiguo y por lo especial de su parroquia (el cual café no nombro porque aún se conserva tan boyante como entonces, aunque más tabernizado); una docena de marinos agrupados de cierta manera y tapados hasta

os desequilíbrios e desajustes iriam desaparecer nas próximas versões.

21 Essas informações se referem aos dados apresentados no ano de 2014, quando fizemos a tradução e verificamos a funcionalidade do corpus para a pesquisa de um tradutor e para o ensino. Atualmente, os dados não são os mesmos, pois a versão está atualizada e ampliada. 
la rodilla con el paño de cubrir la mesa de billar del susodicho café. Los ojos del fantasma eran dos linternas, los cuernos dos tacos, y la causa del ruido metálico, una batería completa de cocina, bien manejada debajo del paño. En cuanto a los berridos, un amigo mío, que por cierto no era marino,

\section{III) Exemplo com o sentido de lugar em que se registra o nascimento:}

de la horca y las mujeres se dividieron en facciones, celebrando a voz en grito el denuedo de cada rival. La cáfila bulliciosa recibía alegremente en su seno al verdugo y le dirigía apodos familiares. Los maleantes vivían y sucumbían sin rencor. Yo estudiaba la anatomía bajo la autoridad de Vesalio y me encaminaba a aquel sitio a descolgar los cadáveres mostrencos. El maestro insistía en las lecciones de la experiencia y me alejaba de escribir disertaciones y argumentos en latín. Uno de los adversarios, de origen desconocido, pereció en el duelo. El registro de ninguna parroquia daba cuenta de su nacimiento ni de su nombre. Fue depositado en una celda de osario y yo la señalé para satisfacer más tarde mis propósitos de estudioso. Nadie podía solicitar las reliquias deplorables, con el fin de sepultarlas afectuosamente. Yo no salgo de la perplejidad al recordar el hallazgo de dos esqueletos en vez del cuerpo lacerado. El cirujano Ramos Sucre, José Antonio Bajo la ráfaga de arena José Antonio Ramos Sucre [146] Una muchedumbre de hormigas había practicado sus galerías en el suelo de nuestra tienda de

Esses três exemplos demonstram o quão importante é a interpretação no contexto de inserção da palavra, oportunidade que o corpus e o gênero textual nos oferecem. No entanto, o corpus como ferramenta nem sempre nos permite tomar a decisão final sobre as escolhas tradutórias. Assim, nessa tentativa de compreensão do significado da palavra Parroquia, constante na certidão de casamento venezuelana que selecionamos para analisar neste trabalho, após a leitura das informações disponibilizadas pelo corpus, precisamos proceder também à busca de informações em dicionários, dentre os quais optamos pelo Dicionário de María Moliner (2014) que nos trouxe a palavra jurisdição como sinônimo de divisão administrativa e distrito.

Por meio dessas análises, portanto, podemos interpretar o termo Parroquia - que aparece pela primeira vez no excerto do gênero textual certidão de casamento - como sinônimo de jurisdição, devido à palavra secretario, a qual significa escrivão em português, e porque, ao seu lado, segue o nome do Município. Não resultaria adequado, de acordo com a nossa interpretação, escolher ciudad (cidade) de Macarao, Municipio Libertador del Distrito 


\section{Capital.}

Já no segundo momento em que a palavra Parroquia aparece na certidão de casamento, acompanhada do nome San Juan, optamos por traduzir como Distrito, por ser uma palavra que, de acordo com o dicionário de María Moliner (2014), somado aos exemplos obtidos pelo corpus pode significar no gênero certidão de casamento tanto território administrativo, quanto bairro.

Desse modo, por meio do corpora disponibilizado pelo CREA e pelo corpus del español del siglo XXI, além da pesquisa realizada, foi possível entender que Parroquia é um falso amigo parcial da língua portuguesa, visto que, além de significar "Igreja", possui também outros significados, como conjunto de indivíduos, distrito, município, bairro, jurisdição, que precisam ser investigados pelo tradutor e no ensino-aprendizagem de tradução.

No excerto do gênero textual que exemplificamos, o vocábulo não assume o sentido de igreja e nem de grupo de indivíduos (clientela).

Neste sentido, o Corpus, indubitavelmente contribui para o trabalho do tradutor, promovendo mais segurança nas decisões a serem tomadas com relação aos signos presentes nos textos que são uma máquina potencial de significados, segundo Arrojo (1999). Além disso, é inegável o fato de que a leitura é contextual, localizada e datada (ARROJO, 1993), e que os sentidos podem alterar-se nos contextos e na passagem do tempo.

Assim, como o tradutor se situa sempre no entre-meio (SOBRAL, 2008), como um aluno que no ensino-aprendizagem assim se sentirá ao enfrentar os conflitos na tomada de decisões, ao realizar as tarefas de tradução, como um leitor-autor que, ao trabalhar entre o deslizar dos enunciados vai atualizando a obra e reenunciando/retextualizando, convém consultar também a linguagem compilada por computadores para que hajam dados mais confiáveis na realização das escolhas na tradução/retextualização.

É com base nas análises feitas em corpora que tornamos mais evidente que a atividade de traduzir não significa transferir ou substituir vocábulos de uma língua para a outra, conforme explica Arrojo (1999), uma vez que o significado somente poderá ser determinado, provisoriamente, por meio de uma leitura, a qual é localizada e situada sócio-historicamente.

Nos exemplos anteriores, utilizados para demonstrar as ocorrências da palavra Parroquia no Corpus de español del Siglo XXI e no CREA, todos os exemplos ilustrados estão presentes no corpus de modo contextualizado, com dados referentes à data e à fonte de 
publicação $^{22}$, ao país em que se utiliza a palavra etc.; e desse modo, conseguimos entender a linguagem de uma forma mais segura.

Entendemos, assim, a relevância atribuída por Baker (1993) ao estudo de Corpus na Tradução. A autora explicita a importância da exploração de bancos de dados de textos traduzidos e, em nosso caso, ainda que não tenhamos analisado textos traduzidos no par de línguas português-espanhol, mas um banco de dados de textos na língua-alvo, pudemos compreender a natureza dos textos e os significados que melhor se identificam com o gênero textual que selecionamos para traduzir, uma vez que esse, considerado o nosso texto-fonte, tratava-se um material de informação que precisávamos analisar, levando em consideração o contexto de uso específico do país, a Venezuela, algo com o qual os dicionários ainda não nos esclarecem por não apresentarem os contextos de usos, mas apenas sinônimos não perfeitos.

Baker (1993) demonstra que há uma necessidade de explorar os recursos que a máquina nos oferece para podermos analisar os contextos, para que as transferências se adequem aos contextos da situação. Assim, por meio desta incipiente pesquisa e reflexão sobre a palavra Parroquia, observamos que, com o auxílio da máquina, podemos optar ainda, com mais segurança - devido ao grande número de dados presente em um corpus - entre as práticas tradutórias com as quais podemos contar ao reformular o texto de chegada.

Os tradutores, desse modo, desenvolvem capacidades de uso da linguagem e assumem a responsabilidade de suas escolhas linguístico-discursivas devido ao respaldo que têm por meio dos dados encontrados em corpus que tratam de usos autênticos da língua. Neste sentido, a Linguística de Corpus contribui não somente como ferramentas de auxílio no trabalho do tradutor, mas também no desenvolvimento de mais capacidades de uso da linguagem que permite ao tradutor realizar com segurança sua intervenção no texto que traduz.

Por essa razão, concebemos que o ensino precisa aliar ferramentas de ensino como corpus e gêneros.

Por essa ótica, repensamos neste trabalho a tarefa de traduzir em um contexto de ensino que precisa promover a apropriação de estratégias aos alunos que lhe permitam traduzir com eficiência nesse contexto de globalização em que se inserem, pois ao direcionarmos o nosso olhar para o corpus, entendemos que as palavras são dinâmicas, portam inúmeros usos e não significam sempre o mesmo.

\footnotetext{
22 Não incluímos todas essas informações abaixo de cada excerto devido ao número de páginas ao qual limitamos este trabalho.
} 


\section{Considerações finais}

O estudo realizado nos possibilitou compreender que a atividade tradutória é resultado de uma condição humana; é uma prática social que evidencia uma necessidade do contexto globalizado.

O exemplo de tradução da certidão de casamento demonstra o efeito das relações internacionais entre os países que promove aos cidadãos o direito de residir em outro país e por isso, a tradução de documentos civis vem tomando cada vez mais espaço nas esferas de tradução pública. Reflete também a variação no uso da língua espanhola que leva os tradutores ao diálogo constante entre os diferentes usos linguísticos que um signo pode apresentar, devido ao fato de a língua espanhola ter usos ora similares, ora diferentes nos 21 países que a utilizam.

Logo, tanto na produção de textos-fonte como textos traduzidos, o uso da linguagem reflete escolhas motivadas, intencionadas e nem sempre transparentes, pois o processo de tradução é um processo de negociação de significados, assim como o processo de produção textual de um gênero em língua materna também espelha escolhas de pensamentos do enunciador.

Em vista desse contexto, entendemos que a linguagem é bastante complexa para ser analisada apenas pela intuição do tradutor que interpreta as definições disponibilizadas somente pelos dicionários semasiológicos dos quais dispõem os tradutores públicos de espanhol-português. E, ainda que o tradutor tenha acesso aos vários tipos de dicionários, a prática tradutória que conta com corpora e com a Linguística de Corpus contribui sobremaneira com a atividade tradutória, visto que corpus, como ferramenta, fornece pistas contextuais sobre determinado uso de gêneros, sentenças, palavras; algo que os dicionários nem sempre podem fazer. Isso justifica a inserção de corpus no ensino de línguas e tradução para fins profissionais em um contexto de internacionalização.

\section{Referências}

ARROJO, R. As relações perigosas entre teoria e políticas de tradução. In: Tradução, desconstrução e psicanálise. Rio de Janeiro: Imago Editora Ltda, 1993.

. Oficina de Tradução. A teoria na prática. São Paulo: Ática, 1999.

BERBER SARDINHA, T. Lista de palavras, concordâncias, palavras-chave: o programa WordSmith Tools. São Paulo: Manole, 2004. 
. Linguística de Corpus e Tradução: prosódia semântica. São Paulo: Manole, 2004. . Visão Geral da Linguística de Corpus. São Paulo: Manole, 2004.

BAKER, M. Corpus Linguistics and Translations Studies. Implications and Applications. Amsterdam/Philadelphia, 1993.

Corpora in Translation Studies: Na Overview and Some Suggestions for Future Research. Target V.7:2, 223-243, 1995.

BENJAMIN, Walter. A tarefa do tradutor. Tradução de Karlheinz Barck et al. Revisão de Johannes Kretschmer. Cadernos de Mestrado/Literatura. Rio de Janeiro: UERJ/Instituto de Letras, 1994.

BRAGA, M.L. A informação, seu fluxo e as construções clivadas. In: Heye, J.(org). Flores verbais. Rio de Janeiro: Nova Fronteira, 1995.

BRASIL. Decreto $n^{\circ} 13.609$, de 21 de outubro de 1943. Rio de Janeiro, Presidência da República do Brasil, Casa Civil, Subchefia para assuntos jurídicos, 1943. Disponível em: http://www.planalto.gov.br/ccivil_03/decreto/1930-1949/D13609.htm. Acesso em: 08.mar.2019.

BRONCKART, J.P. Atividade de Linguagem, discurso e desenvolvimento humano. Tradução de Anna Rachel Machado e Maria de Lourdes Meirelles Matencio [et al.]. Campinas, SP: Mercado de Letras, 2009.

CAStilHO, A. T de. Nova Gramática do Português Brasileiro. São Paulo: Contexto,2012.

CATFORD, J.C. Uma teoria linguística da tradução. São Paulo, Cultrix, 1980.

CINTRÃO, H.P. Traduzindo formas de tratamento do espanhol peninsular ao português de São Paulo: uma visão semiótica e ideológica. In: An. 2. Congr. Bras. Hispanistas Oct. 2002. Disponível em:

$<$ http://www.proceedings.scielo.br/scielo.php?pid=MSC0000000012002000100057\&script $=\mathrm{s}$ ci_arttext>. Acesso em: 28 jun.2012.

DERRIDA, J. Torres de Babel. Trad. de Junia Barreto. Belo Horizonte: UFMG, 2002.

DIK, S. C. The Theory of Functional Grammar. Part 1. The Structure of the Clause. 2nd rev. ed. Berlin: Mouton de Gruyter. New York, 1997.

EZPELETA, P. La noción de género en la planificación de la docencia de la traducción de la primera lengua extranjera. In: El género textual y la traducción. Ano de publicação:2005, Disponível em: <http://www.gentt.uji.es/Publicacions/Ezpelet_ArticuloDidactica1.pdf>. Acesso em: 27 jun.2012.

FAIRCLOUGH, N. Discurso e mudança social. Brasília: Editora Universidade de Brasília: Editora UnB, 2001. 
FISH, S. Is there a text in this class? Tradução de Rafael Eugenio HOYOSANDRADE. Alfa, São Paulo, 36: 189-206, 1992.

GADAMER, Hans-Georg. Man and Language (1966). In: Philosophical Hermeneutics. Trans and Edited by David E. Linge. Berkeley, Cali.: University of California Press, 1976.

HATIM, B; MASON, I. Teoría de la traducción. Una aproximación al discurso. Barcelona: Editora Ariel, S.A, 1995.

HERMANS, T. Translation's other. Inaugural lecture. London: UCL,1996.

HYMES, D.H. Vers la compétence de commucation. Paris: Crédif-Hatier, 1973.

MARCUSCHI, L.A. Anáfora indireta: barco textual e suas âncoras. In: Edwiges Maria Moraro, Ana Christina Bentes (orgs). Referenciação e Discurso. São Paulo: Contexto, 2005.

MEDINA, J.R. Doctrina y testimonio. Venezuela: Dirección de Cultura, Universidad Central de Venezuela, Caracas, 1984.

MOLINER, M. Diccionario de uso del español. Disponível em: $<$ http://www.diclib.com/cgibin/d1.cgi?base $=$ moliner\&page=showpages/ $>$. Acesso em 13 set.2014.

MORÓN, G. El gallo de las espuelas de oro,1986.Venezuela, Caracas: Monte Ávila Editores, 1993.

NEVES, Maria Helena Moura. A Gramática Funcional. São Paulo: Martins Fontes, 1997.

NIDA, E. Language structure and translation. California, Stanford Unviversity Press, 1975.

OLIVEIRA, L.E.M. de. As origens da profissão do tradutor público e intérprete comercial no Brasil. Claritas: revista do departamento de Inglês da Pontíficia Universidade Católica de São Paulo, v.11, n.2, pp25-41, São Paulo, Educ: 2005.

OUSTINOFF, M. Tradução. História, teorias e métodos. Tradução de Marcos Marcionilio. São Paulo: Parábola Editorial,2011.

REAL ACADEMIA ESPAÑOLA: Banco de datos (CREA) [en línea]. Corpus de referencia del español actual. $<$ http://www.rae.es $>$ [acesso 16 de jan. 2019].

. Banco de datos (CREA) [en línea]. Corpus de referencia del español $\overline{\text { actual. }}<$ http://www.rae.es $>$ [acesso $01 \mathrm{de}$ ag. 2014].

REAL ACADEMIA ESPAÑOLA: Banco de datos (Corpus del español del siglo xxi (CORPES) [en línea]. < http://www.rae.es> . [acesso 16 de jan. 2019].

. Banco de datos (Corpus del español del siglo xxi (CORPES) [en línea]. < http://www.rae.es $>$. [acesso 01 de ag. 2014].

RODRIGUES, C.C. Tradução e diferença. S. Paulo: Unesp, 2000. 
SCHNEWLY, B. Gêneros e tipos de discurso: considerações psicológicas e ontogenéticas. In: SCHNEUUWLY, B; DOLZ, J. (orgs.). Gêneros orais e escritos na escola. Tradução de Roxane Rojo e Glaís Sales Cordeiro. Campinas: Mercado de Letras, 2004.

SOBRAL, A. Dizer “o mesmo” a outros: ensaios sobre tradução. São Paulo: SBS, 2008.

TARDIFF, J. "Le transfert des compétences analysé à travers la formation de professionnels", Lyons, Colloque internacional sur le transfert de connaissances, 1994.

TOURY, G. The nature and Role of Norms in Translation. In: idem, Descriptive Translation Studies and Beyond. Amsterdam-Philadelphia: John Benjamins, 1995,53-69.

TRAVAGLIA, N.G. Tradução e retextualização: a tradução numa perspectiva textual. Uberlândia: EDUFU, 2003. 